\section{High-temperature Dip and Low Temperatures for Storage and Disinfestation of Avocados}

\author{
Andrew J. Jessup \\ Horticultural Postharvest Laboratory, New South Wales Agriculture, \\ P. O. Box 581, Gosford, New South Wales 2250, Australia
}

Additional index words. Queensland fruit fly, Dacus tryoni, benomyl, chilling injury, Persea americana

Australian-grown 'Hass' avocados (Persea americana Mill.) will be in oversupply, domestically, within 10 years (Schoorl et al., 1988). A solution is to increase exports. Since Australia is distant from overseas markets, avocados shipped by sea must tolerate extended periods in storage.

An initial study (unpublished data) showed that avocados would tolerate a fungicidal dip ( $0.5 \%$ benomyl at $50 \mathrm{C})$ for $3 \mathrm{~min}$ before being stored at $1 \mathrm{C}$ for at least 20 days. These fruit ripened normally with no evidence of chilling injury (CI). Storage at $1 \mathrm{C}$ for this duration will provide quarantine security against Queensland fruit fly (Qff) (U.S. Dept. Agriculture, 1985), a priority pest in some markets.

This note reports a more detailed study of the effectiveness of long-term storage of 'Hass' avocados at $1 \mathrm{C}$, with or without a prior 50C fungicidal dip, for quarantine security against Qff.

Fruit quality. One-hundred fruit at commercial harvest maturity were collected from five geoclimatic areas in New South Wales and Queensland. Sixty fruit from each location were dipped, 20 at a time, for $3 \mathrm{~min}$ in $0.5 \%$ benomyl at $50 \mathrm{C}$ in a 29 -liter, stainless-steel container. They were then allowed to dry at 18 to $22 \mathrm{C}$ for 2 to $4 \mathrm{~h}$ before being

Received for publication 13 Nov. 1990. The cost of publishing this paper was defrayed in part by the payment of page charges. Under postal regulations, this paper therefore must be hereby marked advertisement solely to indicate this fact. placed at $1 \mathrm{C}$ for up to 30 days. The 40 remaining fruit from each location were stored at $1 \mathrm{C}$ for up to 30 days without a prior $50 \mathrm{C}$ dip. Afterward, fruit were allowed to ripen at 18 to $22 \mathrm{C}$. The period required to reach the edible-ripe stage was recorded. Qualitative measurements were made of skin color, fruit firmness, vascular browning, flesh graying, shrivelling, and internal rot.

Fruit fly mortality. Five-hundred fruit from one orchard on the northern coast of New South Wales were placed on mesh cages housing 20,000 fertile Qff each. Flies were allowed to oviposit into the fruit through the mesh for 4 to $5 \mathrm{~h}$, after which the fruit were removed and stored at $26 \mathrm{C}$ for larval development. Four-hundred of these fruit, containing one of four lifestages (egg, first instar, second instar, or third instar), were subjected to a $50 \mathrm{C}$ fungicidal dip and then $1 \mathrm{C}$ storage for $0,2,3,4,5,6,7$, or 8 days. These fruit and the remaining 100 infested fruit, which were not $50 \mathrm{C}$ dipped or stored at $1 \mathrm{C}$, were stored over sand at $26 \mathrm{C}$ until larval pupation. The criterion for survival was the formation of a normal puparium. The number of survivors from 50C-dipped, 1C-stored fruit were compared with the number from nondipped and non-cold-stored fruit to estimate insect mortality at each period of storage at 1C. Data for the four lifestages were compared by probit analysis (Alvey et al., 1983) to determine the lifestage that was most tolerant of 50C dipping and storage at $1 \mathrm{C}$.

There was little evidence of chilling injury (vascular browning, flesh graying, or uneven ripening) in either the 50C-dipped or the nondipped fruit stored at $1 \mathrm{C}$; however, the $50 \mathrm{C}$ fungicide-dipped, cold-stored fruit were significantly more acceptable $(P<0.05)$ due to the lack of rotting caused by Colletotrichum gloeosporioides (anthracnose). Dipped fruit scored 7 out of 10 for acceptability. Fruit that were neither dipped nor stored at 1C scored 4. Nondipped, 1C-stored fruit remained at the edible-ripe stage for only 3 to 4 days before rotting, whereas fruit dipped at $50 \mathrm{C}$ and stored at $1 \mathrm{C}$ remained in acceptable condition for 7 to 8 days.

Third instar larvae were more tolerant of 50C dipping and $1 \mathrm{C}$ storage than the other infesting lifestages. Probit 9 (99.99683\%) mortality was estimated to occur after a period of 11 days in storage at $1 C$, although there were no survivors following storage at $1 \mathrm{C}$ for 7 or 8 days in this experiment.

Storage of 'Hass' avocados at temperatures below -those currently recommended (Debney et al., 1980) appears to be feasible, provided there is adequate control of spoilage organisms. In these experiments, 'Hass' avocados tolerated storage at $1 \mathrm{C}$ for 30 days after a 50C fungicidal dip. Such a treatment would also provide quarantine security against Qff. The maximum tolerable storage period at $1 \mathrm{C}$ still needs to be determined.

\section{Literature Cited}

Alvey, N.G., C.G. Banfield, R.I. Banter, J.C. Gower, W.J. Krzanowski, and P.W. Lane. 1983. GENSTAT-A general statistical package. Lawes Agricultural Trust, Rothamstead Experimental Station, United Kingdom.

Debney, H.G., K.J. Blacker, B.J. Redding, and J.B. Watkins. 1980. Handling and storage practices for fresh fruit and vegetables. Product Manual, Australian United Fresh Fruit \& Veg. Assn., Product Section-Avocado, Sydney, Australia.

Schoorl, D., D.G. Mayer, and J.E. Holt. 1988 A computer model for forecasting avocado production and marketing demand. Proc. Austral. Avocado Bicentennial Conf., Caloundra, Queensland, Australia, June 1988.

U.S. Department of Agriculture. 1985. United States Department of-Agriculture Animal and Plant Health Inspection Service. Plant Protection and Quarantine Treatment Manual. T107(d). U.S. Dept. Agr., Washington, D.C. 